\title{
Editorial
}

Nephrology

\section{Increasing Interest in Nephrology: Focusing on the Medical Students}

\author{
Anna Burgner T. Alp Ikizler \\ Division of Nephrology and Hypertension, Vanderbilt University Medical Center, Nashville, TN, USA
}

Nephrology, as a discipline, is at a crossroads. There are no diseases that can be better served by further knowledge of the underlying pathogenesis and the development of better therapies and innovative drugs than kidney diseases. Data showing steadily increasing prevalence of patients with kidney disease also point to a need to train further clinical nephrologists to care for patients with chronic kidney disease and end-stage kidney disease. However, during the past decade, there has been a disturbing decrease in interest in Nephrology as a profession among potential trainees. Data from the appointment year 2019 nephrology match show that $37 \%$ or 173 positions went unfilled with $56 \%$ or 92 fellowship training tracks going unfilled [1].

The reasons for the decline in interest in Nephrology are complex and multifactorial (Table 1) $[3,4]$. To date much of the emphasis on increasing interest in nephrology has been directed at internal medicine (IM) residents. However, the decision to pursue a certain subspecialty is often made in medical school with $55 \%$ of post graduate year (PGY)-1 IM resident career plans being concordant with their PGY-3 career plans [2]. Notably, most subspecialty IM fellows report never having considered a career in nephrology citing a lack of role models and the subject matter being too difficult or taught poorly during medical school [3]. These data suggest that trying to increase interest in nephrology by focusing on medical school educa-

\section{KARGER}

(c) 2019 S. Karger AG, Basel

E-Mail karger@karger.com

www.karger.com/ajn tion is an opportunity to increase interest in nephrology. To address this specific issue, the American Society of Nephrology Workforce Committee developed the "Best Practices Project" to isolate translatable methods from the top nephrologist - producing institutions - both medical schools and IM residencies - that could be disseminated and implemented to reverse the declining nephrology interest.

In the current issue of the American Journal of $\mathrm{Ne}$ phrology, Sozio et al. [5] report the initial results of this effort to identify best practices for increasing interest in nephrology in medical school. They identified the 10 medical schools that graduated the highest number of future board-certified nephrologists between 2002 and 2009 and performed directed focus groups with nephrology educators, nephrology training program directors, and a department of medicine chair from 9 of those medical schools. When their answers were analyzed, 4 main themes emerged: (1) Nephrology faculty interaction with medical students, (2) Clinical exposure to nephrology and clinical relevance of renal pathophysiology materials, (3) Use of novel educational methods, and (4) Early exposure to the breadth of nephrology practice. They further present translatable approaches extracted from these themes that can be implemented in other medical schools, including but not limited to increasing nephrology faculty presence on teaching wards as well as at grand rounds 
Table 1. Summarizing reasons cited for not pursuing a career in nephrology $[3,4]$

\begin{tabular}{ll}
\hline Reasons cited for not pursuing a career in nephrology \\
\hline Related to subject matter & $\begin{array}{l}\text { Lack of interest in nephrology } \\
\text { Too difficult of subject matter } \\
\text { Patients are too complex }\end{array}$ \\
\hline Related to education & Lack of role model \\
& Not taught well \\
& Lack of subject exposure \\
\hline Post-training concerns & Opportunity for procedures \\
& $\begin{array}{l}\text { Availability of post-fellowship job } \\
\text { opportunities } \\
\text { Lifestyle is not good } \\
\text { Inadequate financial compensation } \\
\text { Perceptions of unsatisfactory } \\
\text { work-life balance }\end{array}$ \\
\hline
\end{tabular}

and other lectures, offering a wide range of clinical nephrology experiences for medical students, increased use of interactive case-based educational approaches, and summer research programs and mentor programs pairing medical students with nephrologists.

The authors and the American Society of Nephrology (ASN) Workforce Committee should be commended for their efforts to tackle this crucial aspect of nephrology education. Unquestionably, medical students having early and consistent contact with nephrology faculty and exposure to the full breadth of kidney physiology and disease topics is imperative for increasing their interest in nephrology. It is also crucial that nephrology faculty need to be given the time and opportunity to develop and teach the kidney physiology and pathology sections for medical student education. With the ever-increasing pressure to perform clinical duties, most clinician educators may not have an opportunity to participate in these activities unless the institutions provide adequate resources. The academic nephrologists' work allocation should overlap with the academic mission of their respective institutions which undoubtedly includes medical education.

Another important message from this report is the need to use novel educational methods. Medical education has evolved significantly over the last decade with notable advancements in educational methods, mostly designed to create a more effective and engaged environment for the changing needs of the new generation of medical students. Innovative teaching practices such as use of social media and flipping the classroom to ensure that the material is well taught in an engaging manner is the norm. Otherwise students are likely to continue to find the material uninteresting and not relevant and be dissuaded from careers in nephrology [6]. As the authors note, faculty face many competing interests making implementation of these ideas challenging. Learning and implementing these changes into our daily clinical practice is not an easy task. A solution to this concern is to encourage nephrology program directors, renal curriculum teachers, and clinician educators to seek further training in education such as a Masters or Certificate in Health Education, or by participating in local or national educator development programs.

As we refine and revise our approach to nephrology education, we should also be more precise on how and when we implement these changes. A very recent article suggests that while both medical students and residents reported that access to mentors, suitable work-life balance, and an interest in the subject were important factors, medical students and IM residents place emphasis on differing areas when choosing or forgoing nephrology as a subspecialty. Specifically, medical students place more emphasis fellowship competitiveness, length of training, subject exposure, and the opportunity for procedures, whereas residents place a greater emphasis on post fellowship job opportunities [4]. The opportunity here is to match the right trainee with the right trainer. For example, a proceduralist teaching in the medical school renal block curriculum or an experienced private practice clinician as the renal attending rounding with residents could be simple but effective ways to serve the needs of the potential trainees.

While the article makes a strong argument for the aforementioned themes being important in increasing interest in nephrology, it does so with multiple important assumptions and limitations. It presumes that current practices by renal educators in these medical schools is similar to what was occurring in 2002-2009. Over a decade has passed since many of these nephrologists were in medical school, and it is certainly plausible that there could have been significant turnover in faculty as well as changes to curriculum and changes in education techniques used. Were the renal educators interviewed even present at these institutions in 2002-2009 and how much have teaching practices changed since that time frame are important questions not answered in this article. With that said, there will always be a time lapse between the actual observations and outcome measures tracked in studies of this nature.

The study also presumes that is the exposure to nephrology that occurred in medical school is what led ul- 
timately to students choosing nephrology. In the previous mentioned study, almost $45 \%$ of PGY-3 residents that ultimately chose nephrology did not have it as their career plan as a PGY-1 [2] so it very well may have been exposure as a resident rather than as a student that led to their career in nephrology. To address this limitation, the authors plan to also perform structured interviews from the top 10 residency programs that produced the most nephrologists, which would be a very valuable contribution. Finally, these data only reflect what is being performed at those 10 schools and assume that practices at others are significantly different, an assumption that is plausible, but yet to be shown. In addition, these data are mostly ap- plicable to clinical track fellowship recruitment, and strategies targeted toward basic and patient-oriented researchers could be different.

In summary, the report by Sozio et al. [5] is a valuable contribution to our understanding on how to attract medical students to nephrology education. Despite discouraging data to date, there is unprecedented opportunity for us to change the tides and improve interest in nephrology. This could be realistically achieved by active engagement by the right nephrologist at the right time with the right trainee, adapting to contemporary educational methods, and appropriate institutional support for the renal educator with time and remuneration.

\section{References}

1 Pivert KA. 2019 Nephrology Match-Preliminary Results: ASN Data Brief. American Society of Nephrology; 2018, 2019. Available from: https://asndataanalytics.github.io/AY2019-Match/.

2 West CP, Popkave C, Schultz HJ, Weinberger $\mathrm{SE}$, Kolars JC. Changes in career decisions of internal medicine residents during training. Ann Intern Med. 2006 Nov;145(10):774-9.
3 Jhaveri KD, Sparks MA, Shah HH, Khan S, Chawla A, Desai T, et al. Why not nephrology? A survey of US internal medicine subspecialty fellows. Am J Kidney Dis. 2013 Apr;61(4): 540-6.

4 Nair D, Pivert KA, Baudy A 4th, Thakar CV. Perceptions of nephrology among medical students and internal medicine residents: a national survey among institutions with nephrology exposure. BMC Nephrol. 2019 Apr; 20(1):146.
5 Sozio SM, Pivert KA, Shah HH, Chakkera HA, Asmar AR, Varma MR, et al. Increasing Medical Student Interest in Nephrology. Am J Nephrol. DOI: 10.1159/000501058.

6 Rosner M, Parker M, Kohan D. Nephrology as a Career Choice: A Survey of Medical Students (abstract SA-PO2868). J Am Soc Nephrol. 2009;20:767A. 